\title{
Pregnant smokers: Potential for improvement of intervention
}

\author{
Mette Rasmussen ${ }^{1}$, Hanne Tønnesen ${ }^{1,2,3}$
}

\begin{abstract}
Background In many countries, smoking is considered as the most important preventable risk factor for a complicated pregnancy and delivery. However in Denmark, there is no clear picture of pregnant women. The aim was therefore to examine the prevalence, characteristics and registration of maternal smoking and quitting during pregnancy as well as estimate the potential for improvement.
\end{abstract}

Methods This is a cohort study on smoking and quitting prevalence among 422,221 pregnant women in Denmark from 20062012. Data from the Danish National Birth Register was linked with data from the Danish National Smoking Cessation Database in order to identify pregnant smokers undertaking a formalised smoking cessation intervention.

Results Overall, $13 \%$ of the pregnant women were smokers. The smoking prevalence was highest among mothers younger than 25 years of age (29\%) compared to $10-11 \%$ among the other age groups. All prognostic factors in the final analyses were in some way associated with the outcome. A group of 1,279 pregnant women underwent formal smoking cessation intervention programs with follow-up after 6 months. Of these, 232 were registered as non-smokers and 40 had no information on smoking in the Danish National Birth Registry. The potential for reducing smoking among pregnant women was high. 25-32\% more quitters would be expected with a comprehensive Gold Standard Programme for smoking cessation.

Conclusion This study indicates an urgent need for increased focus on offering effective smoking cessation programs to all groups of pregnant smokers, but with a special attention to the youngest group.

doi.org/10.29102/clinhp.150010

\section{About the AUTHORS}

${ }^{1}$ WHO-CC, Clinical Health Promotion Centre, Bispebjerg \&Frederiksberg Hospital, University of Copenhagen ${ }^{2}$ Health Science, University of Southern Denmark ${ }^{3}$ WHO-CC, Clinical Health Promotion Centre, Health Sciences, Lund University

Contact: Mette Rasmussen mette.rasmussen.03@regionh.dk

\section{Introduction}

In many countries, smoking is considered as the most important preventable risk factor for a complicated pregnancy and delivery (1).

Many studies have established an increased risk of serious complications for both mother and child associated with smoking during pregnancy. These include spontaneous abortion, ectopic pregnancy, perinatal mortality, premature birth, low birth weight, congenital malformations, placental abruption, stunted growth, impaired prenatal lung development, and sudden infant death syndrome. Furthermore, there are implications of a connection between smoking during pregnancy and admissions within the first year of life as well as development of behavioural disorders in childhood (1-10).

About 60 thousand children are born in Denmark annually. The usual pathway for pregnant women takes place at the general practitioner and at midwives in Denmark (Figure 1).

In 2001 and 2005 about one in five children were born by a smoker, while about $2 \%$ of the pregnant women stopped

Figure 1 Recommended pathway for pregnancies in Denmark. Each box represents one visit e.g. it is recommended that the first visit at the GP takes place between week 6-10.

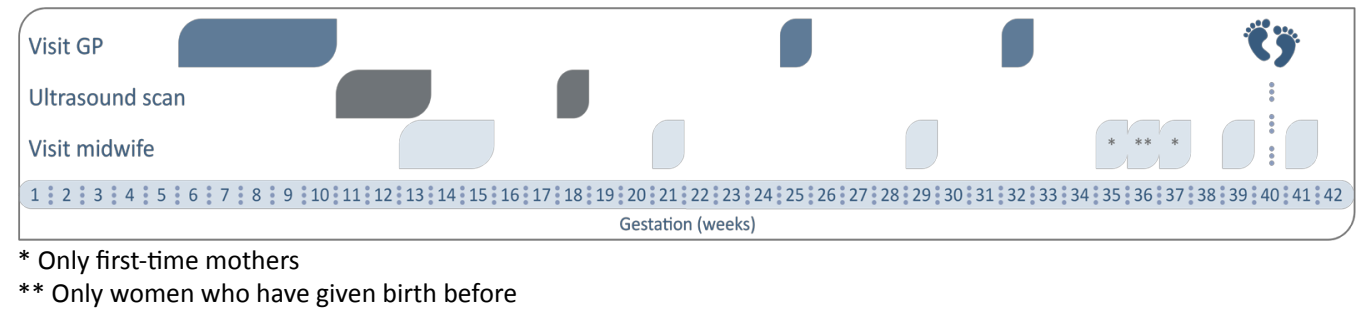




\section{Research and Best Practice}

smoking during their pregnancy (11;12). In a previous Finnish study the prevalence of smokers among Danish pregnant women was high, estimated to $10-12 \%$ in 2010 (13). However, there is no clear picture of the characteristics of the pregnant smokers in Denmark, the validation of the registration of smoking status, or whether they smoke through all or part of the pregnancy.

Our recent research shows that pregnant women have the same high effect of the very intensive 6-weeks Danish standard program (the gold standard program, GSP) for smoking cessation as non-pregnant women. This means that $24-32 \%$ of pregnant women undergoing a GSP course remain continuously smoke-free from end of course and to the follow-up after 6 months (14). Thus, there seems to be a potential for improvement not fully used today.

The aim of this study is therefore to examine the prevalence, characteristics and registration of maternal smoking and quitting during pregnancy as well as estimate the potential for improvement in order to help more pregnant women quit smoking.

\section{Materials and methods}

This was a cohort study based on data from the Danish National Birth Registry (DNBR) and the Danish National Smoking Cessation Database (SCDB) in the period from start 2006 to end 2012. Since 1968 all Danish citizens have been assigned a 10-digit personal identification number (15). These numbers were used for extraction and linkage of data from the two databases; afterwards the data handling was done on anonymous data.

\section{Participants}

The DNBR contains information on every woman giving birth in Denmark, including smoking and quitting status. A total of 422,221 women giving birth have been registered in the study period (Figure 2).

The SCDB contains data on smokers going through a formalised face-to-face smoking cessation programme in Denmark including follow-up on effect after 6 months. 28,659 women have attended a quality assured smoking cessation programme between 20062012. Doublets or entries referring to women attending more than one SCI within the same calendar year were excluded $(\mathrm{n}=1,234)$. Thus, 27,425 women attending a formalised face-to-face smoking cessation intervention between 2006-2012 in Denmark were included in the study (Figure 3).

\section{Data}

The cohort of pregnant women in DNBR was linked to the SCDB, using the personal identification number, to identify those participating in a formalised smoking cessation intervention in Denmark during their pregnancy.

In order to combine a smoking cessation intervention with a pregnancy the intervention had to take place during at least some part of the pregnancy. The duration of a typical smoking cessation intervention in Denmark is 6 weeks, and a pregnancy lasts up to 42 weeks. Therefore, 48 weeks was subtracted from the date of birth to determine the interval of possible dates to have begun the intervention. If a pregnant woman was registered with more than one smoking cessation intervention associated to her pregnancy, the later intervention was used.

Figure 2 Patient flow. Distribution of pregnant women according to smoking status, whether they quit smoking during the pregnancy and finally the time of quitting. Analysis 1-3 corresponds to the analyses reported in table 2.

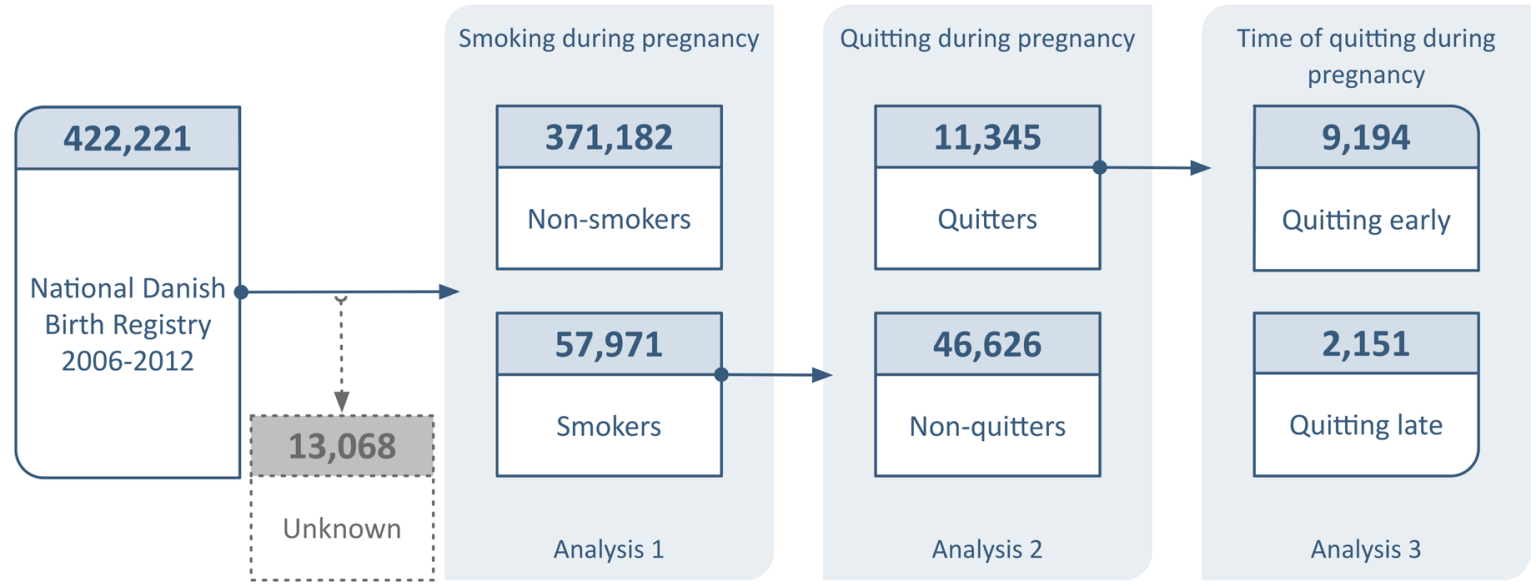




\section{Research and Best Practice}

Figure 3 Number of pregnant smokers and quitters over time. The number of pregnant smokers has decreased constantly during the study period, while the number of women who quit (early or late) during their pregnancy has been relatively stable.

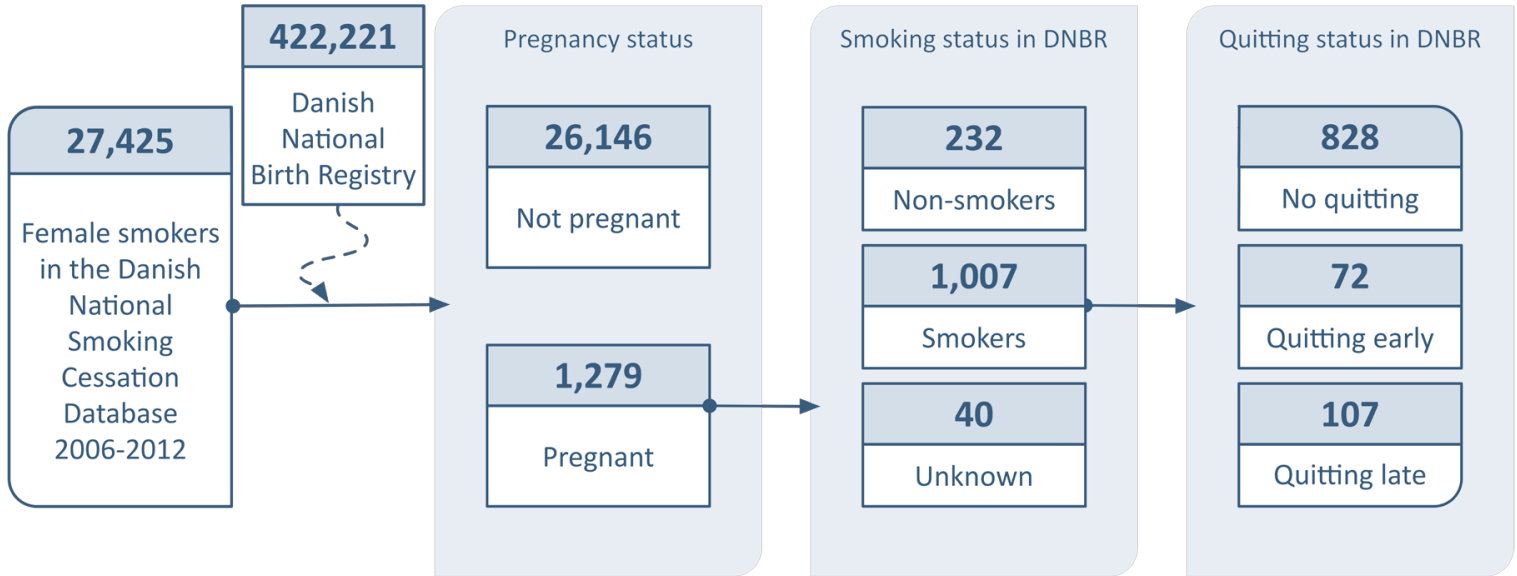

The number of pregnant smokers not undertaking a formalised smoking cessation intervention was calculated, and based on the previous results of GSP among pregnant women (14), the potential for improvement was estimated - assuming that all women went through the GSP smoking cessation intervention.

\section{Outcomes and other variables}

The data on pregnancy and smoking (early and late in pregnancy), year of birth, the mothers age at time of birth, geographic place, number of visits to the general practitioner, midwife and specialist care were extracted from DNBR.

For each patient registered in the SCDB, data on compliance was extracted. Compliance with the programme was defined as having attended at least $75 \%$ of the scheduled meetings (17).

\section{Sub-analysis}

A sub-analysis was performed to evaluate the compliance with the programme for non-pregnant women compared to pregnant women.

\section{Statistics}

All analyses were performed on anonymous data. Characteristics and prevalence were reported as absolute numbers and percentages. Univariate and multivariate logistic regression analyses were used to test for differences in smoking status, quitting and time of quitting. The multivariate logistic analyses were adjusted for the prognostic factors shown in table 2, and they were performed by entering all the predictors together. Patients with missing values were excluded from the analyses. Prognostic factors were identified and results were presented as adjusted odds ratio (OR) with $95 \%$ confidence interval (CI).
The sub-analysis was performed using the Mantel-Haenszel test for stratified $2 \times 2$ tables.

A two-sided $p$ value of $<0.05$ was regarded as statistically significant corresponding to the CI not including the value 1.oo. All statistical calculations were performed with StataIC 14.

\section{Ethics}

The study was approved by the Danish Data Protection Agency (2010-41-5463/2000-54-0013) and registered with the Scientific Ethics Committee (H-CFSP-2010-049). Prior to registration in the SCDB all participants gave informed consent when entering their smoking cessation program. Registration in the DNBR has long been a legal routine for pregnant women as part of the national quality registry legislation.

\section{Results}

Overall, $13 \%$ of the pregnant women were smokers, decreasing from $17 \%$ in the beginning of the research period to $12 \%$ in 2012 (Figure 4).

In the entire cohort, the smoking prevalence was highest among the minor group of mothers younger than 25 years of age (29\%); less than half among those beween 25-34 years of age (11\%) and those of 35 or older (10\%) (Table 1;2).

Also the geographic distribution differed, with the lowest smoking prevalence of $10 \%$ in the Capital Region and the highest of $18 \%$ in the Region Zealand, closest to the Capital Region. 
Figure 4 Number of pregnant smokers and quitters over time. The number of pregnant smokers has decreased constantly during the study period, while the number of women who quit (early or late) during their pregnancy has been relatively stable.

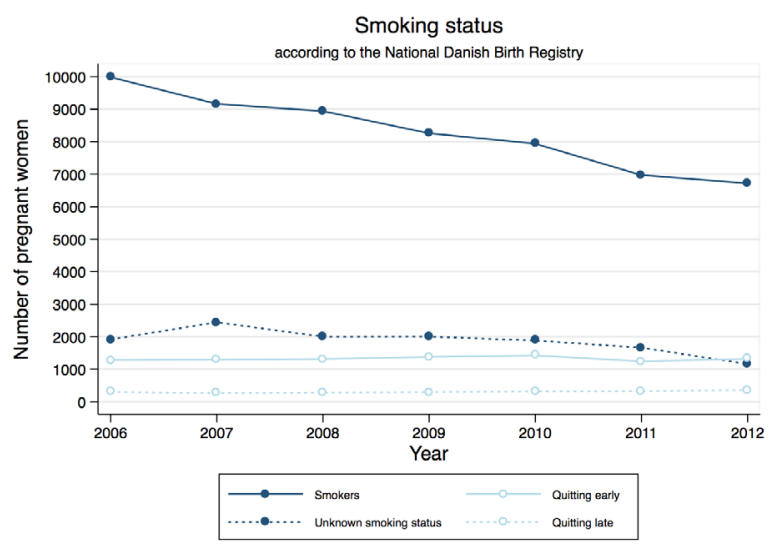

The majority of the women attended the recommended number of visits to the general practitioner and midwife; specialist visits were seldom taking place, which was in accordance with the Danish guidelines (Figure 1). Furthermore, the quality of registration was poor with more than $90 \%$ missing data, since only those being considered for or having received specialist care were probably registered in the DNBR.

Non-smoking was associated with being pregnant in most resent calendar years, older age, giving birth in the Capital Region and following the recommended number of visits to the general practitioner and midwife. The statistically significant prognostic factors for quitting were very similar to non-smoking, except pregnant women in Central Denmark were more likely to quit, and being 25-34 years of age was associated with quitting, while being 35 or older were associated to continuous smoking (Table 2).

Interestingly, the prognostic factors for early quitting were being pregnant in the earliest years of the study period and having no registered visits according to the general guidelines. The group of women who quit during their pregnancy consisted of about $3 \%$ of all the pregnant women. However, the older age of the mother and giving birth in the Capital Region were also prognostic factors for early quitting (Table 2).

The linkage to the SCDB showed that only 1,279 of pregnant women had a formal smoking cessation intervention program during their pregnancy in the study period - but not all of them were registered as smokers in the DNBR. According to the SCDB a total of $232 / 1,279$ (18\%) who had a smoking cessation pro-

\begin{tabular}{|c|c|c|c|c|c|c|c|c|}
\hline \multirow{2}{*}{$\begin{array}{l}\text { Women from } \\
\text { MFR }\end{array}$} & \multicolumn{2}{|c|}{ All } & \multicolumn{2}{|c|}{ Non-smokers } & \multicolumn{2}{|c|}{ Smokers } & \multicolumn{2}{|c|}{ Missing } \\
\hline & $\mathrm{n}$ & (\%) & $\mathrm{n}$ & $(\%)$ & $\mathrm{n}$ & (\%) & $\mathrm{n}$ & $(\%)$ \\
\hline All & 442,221 & $(100)$ & 371,182 & (84) & 57,971 & (13) & 13,068 & (3) \\
\hline \multicolumn{9}{|l|}{ Year of birth } \\
\hline 2006 & 65,607 & (15) & 53,710 & (14) & 9,982 & (17) & 1,915 & (15) \\
\hline 2007 & 65,178 & (15) & 53,572 & (14) & 9,162 & (16) & 2,444 & (19) \\
\hline 2008 & 65,694 & (15) & 54,755 & (15) & 8,939 & (15) & 2,000 & (15) \\
\hline 2009 & 63,531 & (14) & 53,268 & (14) & 8,259 & (14) & 2,004 & (15) \\
\hline 2010 & 64,019 & (14) & 54,200 & (15) & 7,937 & (14) & 1,882 & (14) \\
\hline 2011 & 59,665 & (13) & 51,028 & (14) & 6,972 & $(12)$ & 1,665 & (13) \\
\hline 2012 & 58,527 & (13) & 50,649 & (14) & 6,720 & $(12)$ & 1,158 & (9) \\
\hline \multicolumn{9}{|c|}{ Mothers age (13-66) } \\
\hline$\leq 24$ & 53,020 & $(12)$ & 35,408 & (10) & 15,629 & (27) & 1,983 & (15) \\
\hline $25-34$ & 299,240 & $(68)$ & 257,728 & (69) & 33,122 & $(57)$ & 8,390 & (64) \\
\hline$\geq 35$ & 89,940 & (20) & 78,046 & (21) & 9,220 & $(16)$ & 2,674 & (20) \\
\hline Missing data & 21 & (0) & 0 & (0) & 0 & (0) & 21 & (0) \\
\hline \multicolumn{9}{|c|}{ Hospital geografic area } \\
\hline $\begin{array}{l}\text { Capital } \\
\text { Region }\end{array}$ & 149,427 & (34) & 131,981 & (36) & 15,253 & (26) & 2,193 & (17) \\
\hline $\begin{array}{l}\text { Region } \\
\text { Zealand }\end{array}$ & 52,979 & (12) & 40,799 & (11) & 9,485 & (16) & 2,695 & (21) \\
\hline $\begin{array}{l}\text { South Den- } \\
\text { mark }\end{array}$ & 87,017 & (19) & 71,607 & (19) & 13,199 & (23) & 2,211 & (17) \\
\hline $\begin{array}{l}\text { Central } \\
\text { Denmark }\end{array}$ & 106,908 & (24) & 90,080 & (24) & 13,497 & (23) & 3,331 & (25) \\
\hline $\begin{array}{l}\text { North Den- } \\
\text { mark }\end{array}$ & 39,026 & (9) & 32,738 & (9) & 6,026 & (10) & 262 & (2) \\
\hline Home births & 4,465 & (1) & 3,846 & (1) & 497 & (1) & 122 & (1) \\
\hline Missing data & 2,399 & (1) & 131 & (0) & 14 & (0) & 2,254 & (17) \\
\hline \multicolumn{9}{|c|}{ Visits at general practitioner } \\
\hline No visits & 15,521 & (4) & 12,672 & (3) & 2,487 & (4) & 362 & (3) \\
\hline $1-2$ visits & 82,441 & (19) & 67,085 & (18) & 13,177 & $(23)$ & 2,179 & (17) \\
\hline 3 visits* & 250,288 & $(57)$ & 215,278 & $(58)$ & 30,227 & $(52)$ & 4,783 & (37) \\
\hline$>3$ visits & 30,454 & (7) & 25,754 & (7) & 4,041 & (7) & 659 & (5) \\
\hline Missing data & 63,517 & (14) & 50,393 & (14) & 8,039 & (14) & 5,085 & (39) \\
\hline \multicolumn{9}{|c|}{ Visits at midwife } \\
\hline No visits & 16,063 & (4) & 12,964 & (3) & 2,699 & (5) & 400 & (3) \\
\hline $1-3$ visits & 61,198 & (14) & 50,378 & (14) & 9,444 & $(16)$ & 1,376 & (11) \\
\hline 4-7 visits* & 319,974 & $(72)$ & 273,882 & (74) & 40,275 & (69) & 5,817 & (45) \\
\hline$>7$ visits & 15,560 & (4) & 12,514 & (3) & 2,642 & (5) & 404 & (3) \\
\hline Missing data & 29,426 & (7) & 21,444 & (6) & 2,911 & (2) & 5,071 & (39) \\
\hline \multicolumn{9}{|c|}{ Visits at medical specialist } \\
\hline No visits & 845 & (0) & 758 & (0) & 63 & (0) & 24 & (0) \\
\hline $1-2$ visits & 2,096 & (0) & 1,825 & (0) & 232 & (0) & 39 & (0) \\
\hline 3 visits & 677 & (0) & 574 & (0) & 90 & (0) & 13 & (0) \\
\hline$>3$ visits & 427 & (0) & 355 & (0) & 65 & (0) & 7 & (0) \\
\hline Missing data & 438,176 & (99) & 367,670 & (99) & 57,521 & (99) & 12,985 & (99) \\
\hline
\end{tabular}

Smokers include all women who declared that they smoked at some point of their pregnancy. *Recommended number of visits. 


\section{Research and Best Practice}

Table 2 Analyses of women giving birth from 2006-2012.

\begin{tabular}{|c|c|c|c|}
\hline \multirow[t]{2}{*}{ Women in MFR } & $\begin{array}{l}\text { Analysis } 1 \\
\text { Smoking status }\end{array}$ & $\begin{array}{l}\text { Analysis } 2 \\
\text { Quitting }\end{array}$ & $\begin{array}{l}\text { Analysis } 3 \\
\text { Time of quitting }\end{array}$ \\
\hline & $\begin{array}{l}\text { Adjusted ORs } \\
(95 \% \mathrm{Cl}) \\
(\mathrm{n}=422,221)\end{array}$ & $\begin{array}{l}\text { Adjusted ORs } \\
(95 \% \mathrm{Cl}) \\
(\mathrm{n}=57,971)\end{array}$ & $\begin{array}{l}\text { Adjusted ORs } \\
(95 \% \mathrm{Cl}) \\
(\mathrm{n}=11,345)\end{array}$ \\
\hline \multicolumn{4}{|l|}{ Year of birth } \\
\hline 2006 & 1 & 1 & 1 \\
\hline 2007 & $0.91(0.88-0.94)$ & $0.88(0.81-0.95)$ & $0.82(0.69-0.99)$ \\
\hline 2008 & $0.84(0.82-0.87)$ & $0.83(0.76-0.89)$ & $0.87(0.73-1.04)$ \\
\hline 2009 & $0.81(0.78-0.83)$ & $0.70(0.65-0.76)$ & $0.87(0.73-1.04)$ \\
\hline 2010 & $0.78(0.68-0.81)$ & $0.64(0.59-0.69)$ & $0.89(0.74-1.06)$ \\
\hline 2011 & $0.71(0.69-0.74)$ & $0.62(0.57-0.67)$ & $1.08(0.90-1.28)$ \\
\hline 2012 & $0.68(0.66-0.71)$ & $0.54(0.50-0.58)$ & $1.10(0.92-1.30)$ \\
\hline \multicolumn{4}{|l|}{ Mothers age (13-66) } \\
\hline$\leq 24$ & 1 & 1 & 1 \\
\hline $25-34$ & $0.31(0.30-0.32)$ & $0.87(0.83-0.92)$ & $0.66(0.60-0.74)$ \\
\hline$\geq 35$ & $0.29(0.28-0.29)$ & $1.21(1.13-1.29)$ & $0.76(0.65-0.89)$ \\
\hline \multicolumn{4}{|c|}{ Hospital geografic area } \\
\hline Capital Region & 1 & 1 & 1 \\
\hline Region Zealand & $1.83(1.77-1.88)$ & $1.77(1.65-1.90)$ & $1.30(1.09-1.55)$ \\
\hline South Denmark & $1.51(1.48-1.55)$ & $1.26(1.19-1.34)$ & $1.83(1.60-2.10)$ \\
\hline Central Denmark & $1.34(1.30-1.37)$ & $0.88(0.83-0.93)$ & $1.95(1.72-2.22)$ \\
\hline North Denmark & $1.84(1.69-2.00)$ & $1.72(1.58-1.86)$ & $1.29(1.05-1.59)$ \\
\hline Home births & $1.18(1.07-1.31)$ & $2.15(1.63-2.84)$ & $2.44(1.36-4.38)$ \\
\hline \multicolumn{4}{|c|}{ Visits at general practitioner } \\
\hline No visits & $1.01(0.90-1.14)$ & $1.31(1.18-1.46)$ & $0.65(0.48-0.87)$ \\
\hline $1-2$ visits & $1.34(1.31-1.37)$ & $1.36(1.29-1.43)$ & $1.21(1.07-1.36)$ \\
\hline 3 visits (reference) & 1 & 1 & 1 \\
\hline$>3$ visits & $1.04(1.00-1.08)$ & $0.89(0.83-0.97)$ & $0.99(0.83-1.18)$ \\
\hline \multicolumn{4}{|l|}{ Visits at midwife } \\
\hline No visits & $1.49(1.32-1.67)$ & $1.43(1.28-1.59)$ & $0.72(0.54-0.95)$ \\
\hline $1-3$ visits & $1.17(1.14-1.20)$ & $1.49(1.40-1.59)$ & $1.22(1.06-1.40)$ \\
\hline $\begin{array}{l}4-7 \text { visits (refe- } \\
\text { rence) }\end{array}$ & 1 & 1 & 1 \\
\hline$>7$ visits & $1.23(1.18-1.29)$ & $1.15(1.04-1.27)$ & $1.35(1.09-1.68)$ \\
\hline
\end{tabular}

Smoking status: ORs with $95 \% \mathrm{Cl}$ for non-smokers vs. smokers for the prognostic factors of the adjusted multivariable analyses are presented.

Pregnant smokers who quits or continuous to smoke during pregnancy: ORs with $95 \% \mathrm{Cl}$ for quitters vs. smokers for the prognostic factors of the adjusted multivariable analyses are presented.

gram with follow-up after 6 months were registered as non-smokers; another 40/1,279 (3\%) without information on smoking status in DNBR had also undertaken an intervention to quit smoking.

The relatively high number of pregnant smokers could potentially benefit from the comprehensive Danish 6 weeks Gold Standard Program (GSP) (14). The GSP has been shown to have a continuous abstinence rate for pregnant women of $24.5-32.0 \%$ after 6 months, with a follow-up of $76 \%$.
The exact number of pregnant smokers in DNBR was 57,971. Except for the 1,279 smokers already attending a smoking cessation intervention, the potential target group consisted of 56,692 smokers. The potential number of extra successful quitters would then be $13,890-$ 18,141 pregnant women in the research period, if all pregnant smokers undertook the GSP.

\section{Sub-analysis}

The sub-analysis revealed no difference in compliance between pregnant and non-pregnant women, when stratified by age categories $(\mathrm{OR}=0.95,95 \% \mathrm{CI}$ : $0.84-$ 1.08).

\section{Discussion}

This Danish cohort study of more than 400 thousand pregnant women showed a relatively high frequency of smokers, though decreasing over the study period from 2006-2012. On average, one of eight pregnant women have been smoking at some point during their pregnancy, but almost three times as many among the youngest women up to mid-twenties compared to the other age groups. Statistically significant prognostics being a non-smoker and an early quitter were giving birth in the capital Region and being twenty-five years of age or older, both representing the majority of participants within each group.

Only a noteworthy small group of the pregnant smokers undertook a formal smoking cessation program with follow-up on effect after 6 months according to the SCDB; and interestingly, almost one in five of those were actually registered as non-smoker in the DNBR. The potential for improvement showed to be extreme.

The prevalence of Danish pregnant smokers was lower than the prevalence of smoking in the general population, which is a result also found in other countries (13). However, it is still very high, with a large room for improvement. If all the pregnant women attended a GSP, a further reduction of smoking during pregnancy would be about $25-32 \%$ (14). GSP is a 6-week manual based education program for smokers including individual counselling on the use of nicotine replacement therapy based on Fagerströms score for nicotine dependency and administered according to the smoker's preference, or other pharmaceutical support (16). In Denmark nicotine replacement therapy during pregnancy is recommended only to women who continue to smoke at least 10 cigarettes a day after the 1 . trimester, if the alternative is continuously smoking. 


\section{Research and Best Practice}

A recent review has shown that unfortunately, almost half of the pregnant quitters seems to relapse about 6 months after pregnancy without major differences beween self-reported and validated quit-rates (17). Therefore, it would be relevant to rethink and evaluate new smoking cessation programs for pregnant smokers (18).

The big difference in smoking prevalence throughout the country and the very high prevalence among the youngest group of women are directly reflecting the background population. However, other major differences are identified in relation to socio-economic conditions, which may also be of influence on the smoking status during pregnancy. Unfortunately, no clear strategies have been developed to effectively reduce the socio-economic gradient in smoking (19). However, to reduce the number of smokers GSP seems effective across this gradient (20).

The study has both strength and weaknesses. The use of self-reported outcomes is a weakness, because the successful quitting may be overestimated with approximately 3-6\% (21-24). This may be even more pronounced during pregnancy, and in this study smokers also claimed to be non-smokers. The overestimation has been described before (25).

About $4 \%$ of the pregnant women had no registered visits to the general practitioner and/or the mid-wife according to the DNBR. Overall, the frequency of missing data on visits are high compared to the other information in the DNBR, including information of smoking status. While the first introduces a bias, the last is a strength. In previous studies compliance has shown to be by far the most important predictor for being continuously abstinent 6 months after attending a GSP intervention $(14 ; 16 ; 20)$. The sub-analysis revealed no difference in compliance rates between pregnant and non-pregnant smokers. This strengthens the estimation of the potential number of extra successful quitters among pregnant women. Nevertheless, the results should be interpreted and implemented with caution. In view of the results of this study it is urgently needed to increase the focus and activities to reach out to more pregnant smokers - including the youngest women with effective smoking cessation programs. Prevention and early quitting would be very important for the individual pregnant woman and the child. It would also be beneficial to public health in general.

\section{Conclusion}

This study indicates an urgent need for increased focus on offering effective smoking cessation programs to all groups of pregnant smokers, but with a special attention to the youngest group.

\section{Author Contributions}

MR performed the data handling and analyses. Both authors developed the project idea, interpreted the results, participated in writing and editing the article, approved the final edition and guaranteed the content.

\section{Conflicts of Interest}

The authors declare no conflict of interest. 


\section{Research and Best Practice}

\section{References}

(1) Cnattingius, S. The epidemiology of smoking during pregnancy: smoking prevalence, maternal characteristics, and pregnancy outcomes. Nicotine Tob. Res. Off. J. Soc. Res. Nicotine Tob. 2004, 6 Suppl 2, S125-40.

(2) Schneider, S.; Huy, C.; Schütz, J.; Diehl, K. Smoking cessation during pregnancy: a systematic literature review. Drug Alcohol Rev. 2010, 29, 81-90.

(3) Wisborg, K.; Henriksen, T. B. Tobak og graviditet. Er der behov for forebyggelse? Findes der effektive metoder? [Tobacco and Pregnancy. Is there a need for prevention? Are there effective methods?]; 1,0 ed.; Sundhedsstyrelsen, 2003.

(4) Wisborg, K.; Kesmodel, U.; Henriksen, T. B.; Olsen, S. F.; Secher, N. J. Exposure to tobacco smoke in utero and the risk of stillbirth and death in the first year of life. Am. J. Epidemiol. 2001, 154, 322-7.

(5) McDonnell-Naughton, M.; McGarvey, C.; O’Regan, M.; Matthews, T. Maternal smoking and alcohol consumption during pregnancy as risk factors for sudden infant death. Ir. Med. J. 2012, 105, 105-8.

(6) Wisborg, K.; Kesmodel, U.; Henriksen, T. B.; Olsen, S. F.; Secher, N. J. A prospective study of smoking during pregnancy and SIDS. Arch. Dis. Child. 2000, 83, 203-6.

(7) Wisborg, K.; Henriksen, T. B.; Obel, C.; Skajaa, E.; Ostergaard, J. R. Smoking during pregnancy and hospitalization of the child. Pediatrics 1999, 104, e46

(8) Andres, R. L.; Day, M. C. Perinatal complications associated with maternal tobacco use. Semin. Neonatol. SN 2000, 5, 231-41.

(9) Yang, Q.; Wen, S. W.; Phillips, K.; Oppenheimer, L.; Black, D.; Walker, M. C. Comparison of maternal risk factors between placental abruption and placenta previa. Am. J. Perinatol. 2009, 26, 279-86.

(10) Shah, N. R.; Bracken, M. B. A systematic review and meta-analysis of prospective studies on the association between maternal cigarette smoking and preterm delivery. Am. J. Obstet. Gynecol. 2000, 182, 465-72.

(11) Nye tal fra Sundhedsstyrelsen: Fødselsregisteret 1997 - 2001; 2001.

(12) Egebjerg Jensen, K.; Jensen, A.; Nøhr, B.; Krüger Kjaer, S. Do pregnant women still smoke? A study of smoking patterns among 261,029 primiparous women in Denmark 1997-2005. Acta Obstet. Gynecol. Scand. 2008, $87,760-7$.

(13) Ekblad, M.; Gissler, M.; Korkeila, J.; Lehtonen, L. Trends and risk groups for smoking during pregnancy in Finland and other Nordic countries. Eur. J. Public Health 2013.

(14) Rasmussen, M.; Heitmann, B. L.; Tønnesen, H. Effectiveness of the Gold Standard Programmes (GSP) for Smoking Cessation in Pregnant and Non-Pregnant Women. Int. J. Environ. Res. Public Health 2013, 10, 36533666.
(15) Frank, L. Epidemiology. When an entire country is a cohort. Science 2000, 287, 2398-9.

(16) Neumann, T.; Rasmussen, M.; Heitmann, B. L.; Tønnesen, H. Gold Standard Program for Heavy Smokers in a Real-Life Setting. Int. J. Environ. Res. Public Health 2013, 10, 4186-4199.

(17) Jones, M.; Lewis, S.; Parrott, S.; Wormall, S.; Coleman, T. Re-starting smoking in the postpartum period after receiving a smoking cessation intervention: a systematic review. Addiction 2016, 111, 981-90.

(18) Leung, L. W. S.; Davies, G. A. Smoking Cessation Strategies in Pregnancy. J. Obstet. Gynaecol. Canada JOGC = J. d'obstétrique gynécologie du Canada JOGC 2015, 37, 791-7.

(19) Courtney, R. J.; Naicker, S.; Shakeshaft, A.; Clare, P.; Martire, K. A.; Mattick, R. P. Smoking Cessation among Low-Socioeconomic Status and Disadvantaged Population Groups: A Systematic Review of Research Output. Int. J. Environ. Res. Public Health 2015, 12, 6403-22.

(20) Neumann, T.; Rasmussen, M.; Ghith, N.; Heitmann, B. L.; Tønnesen, H. The Gold Standard Programme: smoking cessation interventions for disadvantaged smokers are effective in a real-life setting. Tob. Control 2013, 22, Epub 2012 Jun 16.

(21) Lumley, J.; Chamberlain, C.; Dowswell, T.; Oliver, S.; Oakley, L.; Watson, L. Interventions for promoting smoking cessation during pregnancy. Cochrane Database Syst. Rev. 2009, CD001055.

(22) Ferguson, J.; Bauld, L.; Chesterman, J.; Judge, K. The English smoking treatment services: one-year outcomes. Addiction 2005, 100 Suppl, 59-69. (23) Judge, K.; Bauld, L.; Chesterman, J.; Ferguson, J. The English smoking treatment services: short-term outcomes. Addiction 2005, 100 Suppl, 46-58.

(24) Pisinger, C.; Vestbo, J.; Borch-Johnsen, K.; Thomsen, T.; Jørgensen, T. Acceptance of the smoking cessation intervention in a large population-based study: the Inter99 study. Scand. J. Public Health 2005, 33, 138-45.

(25) Tong, V. T.; Althabe, F.; Alemán, A.; Johnson, C. C.; Dietz, P. M.; Berrueta, M.; Morello, P.; Colomar, M.; Buekens, P.; Sosnoff, C. S.; Farr, S. L.; Mazzoni, A.; Ciganda, A.; Becú, A.; Bittar Gonzalez, M. G.; Llambi, L.; Gibbons, L.; Smith, R. A.; Belizán, J. M. Accuracy of self-reported smoking cessation during pregnancy. Acta Obstet. Gynecol. Scand. 2015, 94, 106-11. 